Глава 4. Биотехнология растений

\title{
THE EFFECT OF HAZELNUT SHOOTS PRETREATMENT ON THE EFFICIENCY OF INTRODUCING EXPLANTS INTO IN VITRO CULTURE
}

\author{
Rakhmangulov R. S., Malyarovskaya V. I., Samarina L. S. \\ Federal State Budgetary Scientific Institution \\ "Russian Research Institute of Floriculture and Subtropical Crops", \\ c. Sochi, Russia, e-mail: rakhmaruslan@yandex.ru
}

The main problems of introducing hazelnut into in vitro culture are a high degree of endogenous fungal contamination, phenolic oxidation of tissues and necrosis of explants due to surface sterilization. In this regard, the purpose of present work is to reveal the effect of fungicide pretreatment on the effectiveness of obtaining aseptic culture of hazelnut explants. As a result of the research, it was found that when using pre-treatment of shoots by fungicides, the percentage of aseptic viable explants was $16.6-56 \%$, depending on sterilization procedure. In variants without fungicide pretreatment, the rate of aseptic explants was $0 \%$. The best variant of sterilization was the treatment of shoots with $10 \%$ Bleach for $7 \mathrm{~min}$, while the rate of sterile viable explants was $56 \%$, necrosis $10 \%$ and contamination $33.3 \%$. The results obtained will be useful for creating in vitro collection of valuable hazelnut genotypes and for the development of micropropagation protocols.

Key words: Corylus avellana, micropropagation, aseptic culture, decontamination, sodium hypochlorite.

УДК 635.9:631.52:581.143.6

\section{НЕКОТОРЫЕ АСПЕКТЫ КЛОНАЛЬНОГО МИКРОРАЗМНОЖЕНИЯ ЛИЛИЙ}

Соколова М. А.
Федеральное государственное бюджетное научное учреждение «Федеральный научный ичентр им. И. В. Мичурина»,
2. Мичуринск, Россия, e-mail: marina-111012@rambler.ru

В статье представлены результаты клонального микроразмножения сортообразцов лилий, относящихся к разным разделам Международной классификации гибридных лилий: Азиатским и Трубчатым гибридам. Приведены экспериментальные данные по стерилизации растительного материала лилий на этапе введения в культуру in vitro. На этапе собственно микроразмножения, в зависимости от минерального состава питательных сред, отмечены сортовые особенности, отразившиеся на регенерации, образовании, а также, на дальнейшем росте и развитии адвентивных луковичек лилий.

Ключевые слова: лилии, клональное микроразмножение, стерилизация, контаминация, регенерация, коэффициент размножения. 
Лилии - многолетние луковичные растения семейства лилейных (Liliaceae). Многообразие форм, окрасок околоцветника, высоты растений и сроков цветения открывают широкие перспективы для использования этих растений в озеленении, для срезки и выгонки $[3,4]$.

В ФГБНУ «ФНЦ им. И. В. Мичурина» благодаря плодотворной работе отечественного селекционера лилий М. Ф. Киреевой и её коллег Ивановой Н. В., Мартыновой В. В., Коршиковой Н. Г., Пугачёвой Г. М. создано свыше 100 высокодекоративных сортов Азиатских и Трубчатых лилий, имеющих универсальное назначение, получивших признание не только в нашей стране, но и за рубежом [2].

Однако нередко высокодекоративные и устойчивые сорта, отборные и элитные формы лилий, характеризуются низким коэффициентом вегетативного размножения. Достаточно быстро размножить посадочный материал позволяет метод клонального микроразмножения.

Объекты и методы исследований. Объектами исследований являлись сортообразцы, относящиеся к разделу Азиатских гибридов лилий (сорт 'Андриана') и Трубчатых гибридов лилий (отборный сеянец 161-103-4) селекции ФГБНУ «ФНЦ им. И. В. Мичурина».

Цель исследований: подбор минерального состава питательных сред для увеличения коэффициента размножения и размера адвентивных луковичек Азиатских и Трубчатых гибридов лилий на этапе собственно микроразмножения.

Работа проводились в 2010-2011 гг. на базе отдела декоративного садоводства и лаборатории биотехнологии ФНЦ им. И. В. Мичурина согласно методике [1], с некоторыми изменениями применительно к культуре лилий.

В качестве исходного растительного материала на этапе введения в культуру использовали чешуи луковиц, прошедшие период покоя в течение двух месяцев при $\mathrm{t}=+4-6^{\circ} \mathrm{C}$. Растительный материал стерилизовали 50\%-ным раствором «Белизны» в течение 10 минут. На этапе пролиферации размножение проводили чешуйками с адвентивных луковичек.

На этапе введения экспланты высаживали на питательную среду, состоящую из минеральных солей по прописи Мурасиге-Скуга. На этапе собственно микроразмножения использовали питательные среды Мурасиге-Скуга - контроль; 1/2 Мурасиге-Скуга (состав всех минеральных элементов, уменьшенный вдвое); Кворина-Лепуавра; 1/2 КворинаЛепуавра (состав всех минеральных элементов, уменьшенный вдвое). В качестве регулятора роста в питательные среды добавляли НУК ( $\alpha$-нафтилуксусную кислоту) в концентрации 0,1 мг/л. В питательные среды добавляли 60 г/л сахарозы, 8 г/л агара; $\mathrm{pH}$ среды 5,7. Продолжительность одного пассажа - 6-8 недель. Адвентивные луковички выращивали в лабораторных условиях в темноте при температуре $20-23{ }^{\circ} \mathrm{C}$. 
Результаты и их обсуждение. В результате проведённых исследований было установлено, что на этапе введения в культуру in vitro контаминация была низкой и составила 6,7 \%. Наряду с освобождением от инфекции растительного материала, стерилизация сопровождалась гибелью эксплантов. Так, количество эксплантов, оставшихся без развития, было 31,7 \%. Регенерация эксплантов отмечалась на уровне 61,6 \%.

На этапе собственно микроразмножения количество образовавшихся адвентивных луковичек зависело от сортовых особенностей и минерального состава питательных сред. Так, у сорта 'Андриана' показатель коэффициента размножения имел небольшой размах варьирования и находился в пределах от 2,1 (на питательной среде 1/2 Кворина-Лепуавра и в контроле) до 2,3 шт./эксплант (на среде Кворина-Лепуавра с полным минеральным составом) $\left(F_{\text {факm. }}<F_{\text {теор. }}\right)$ (рис. 1$)$.

У гибридного сеянца 161-103-4 максимальный коэффициент размножения отмечался на питательной среде 1/2 Кворина-Лепуавра, где образовалось 3,8 луковичек на один эксплант, что выше, чем в контрольном варианте на 27 \%. Наименьшее количество луковичек у этого сортообразца образовалось на среде 1/2 Мурасиге-Скуга - 2,5 шт.эксплант, что ниже контрольного значения на $17 \%\left(\mathrm{HCP}_{05}=0,5\right)$.

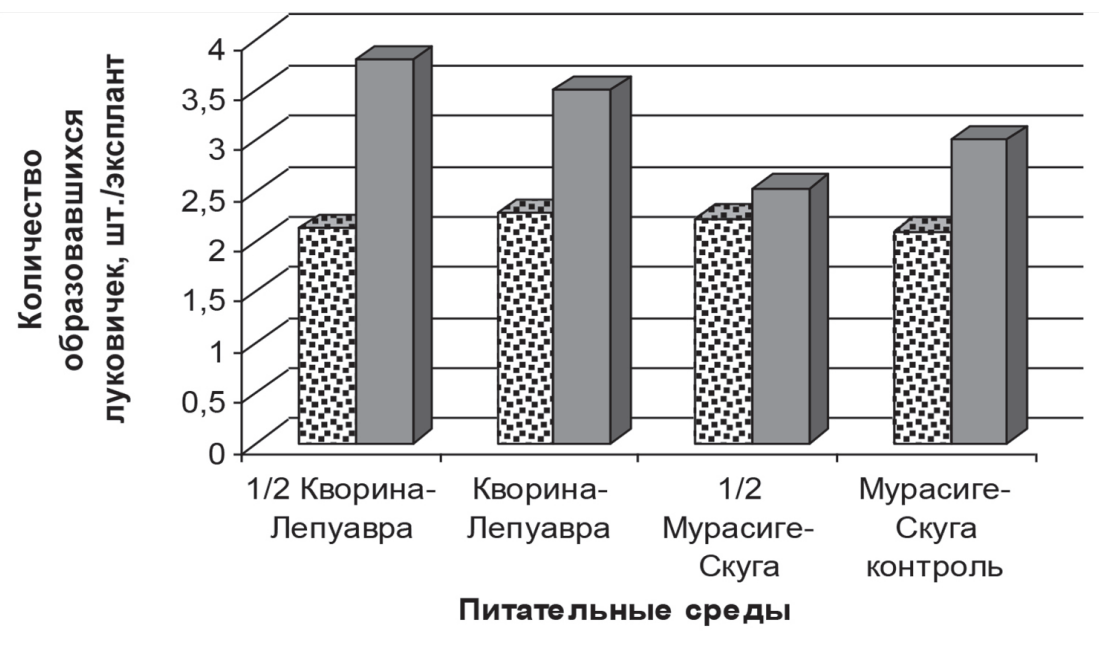

国 сорт “Андриана' $\quad \square$ отборный сеянец 161-103-4

Рис. 1. Влияние минерального состава питательных сред на коэффициент размножения

Диаметр образовавшихся луковичек также зависел от сортовых особенностей. 
У сорта ‘Андриана' наибольшего среднего диаметра - 3,3 мм - адвентивные луковички достигли в контрольном варианте, а на питательной среде 1/2 Кворина-Лепуавра их размер был меньше контрольных значений на $24 \%\left(\mathrm{HCP}_{05}=0,3\right)$. У гибридного сеянца 161-103-4 максимальный средний диаметр отмечался у адвентивных луковичек, образовавшихся на питательной среде 1/2 Мурасиге-Скуга - 6,3 мм, а минимальный - 5,1 мм на питательной среде $1 / 2$ Кворина-Лепуавра $\left(\mathrm{HCP}_{05}=0,5\right)$ (рис. 2).

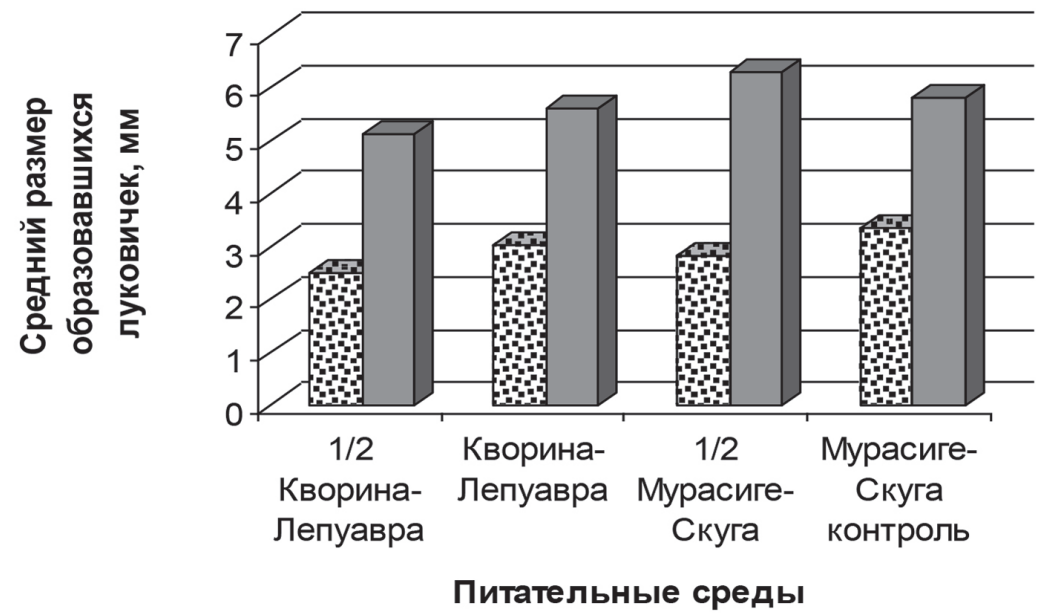

四 сорт 'Андриана' $\quad \square$ отборный сеянец 161-103-4

Рис. 2. Влияние минерального состава питательных сред на размер адвентивных луковичек

Заключение. Таким образом, в результате проведённых исследований установлено, что на этапе собственно микроразмножения отмечались ярко выраженные сортовые особенности. У сорта 'Андриана' различный минеральный состав питательных сред не привёл к значительному повышению коэффициента, этот показатель находился в пределах ошибки опыта, достигнув значения 2,1-2,3 шт./эксплант. Наибольший средний диаметр адвентивных луковичек сорта 'Андриана' был отмечен в контрольном варианте - на питательной среде Мурасиге-Скуга с полным минеральным составом. На увеличение коэффициента размножения отборного сеянца 161-103-4 существенное влияние оказал минеральный состав питательной среды Кворина-Лепуавра, уменьшенный вдвое. Максимального среднего диаметра - 6,3 мм - адвентивные луковички у этого сортообразца достигли на питательной среде Мурасиге-Скуга с минеральным составом, уменьшенным вдвое. 
Глава 4. Биотехнология растений

\section{Библиографический список}

1. Выхристова Г.И. Методические указания по регенерации и размножению нарциссов в культуре ткани. - Сочи, 1986. - 17 с.

2. Киреева М.Ф. Зимостойкие лилии // Цветоводство. - 2004. - № 4. - С. 14-16. ISSN: 0041-4905.

3. Киреева М.Ф. Лилии. - М.: Россельхозиздат, 1984. - 206 с.

4. Мерзлякова Н.В. Итоги сортоиспытания лилий в условиях Северо-западной зоны РСФСР: сб. науч. тр. - Мичуринск: ВНИИ садоводства им. И. В. Мичурина, 1988. Вып. 52. - С. 29-32.

\section{SOME ASPECTS OF LILIES CLONAL MICROPROPAGATION}

\section{Sokolova M. A.}

Federal State Budgetary Scientific Institution "Federal Research Centre named after I. V. Michurin", c. Michurinsk, Russia, e-mail: marina-111012@rambler.ru

The paper presents the results of clonal micropropagation of lilies cultivars belonging to different sections within hybrid lilies International classification: Asiatic and Trumpet hybrids. Experimental data on sterilization of lilies plant material at the stage of introducing into in vitro culture are presented. At the stage of micropropagation itself, depending on the mineral composition of nutrient media, varietal characteristics were noted, which affected the regeneration, formation and further growth and development of adventitious lilies bulbs.

Key words: lilies, clonal micropropagation, sterilization, contamination, regeneration, propagation coefficient. 